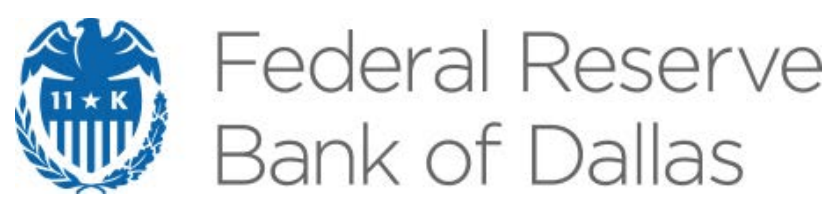

\title{
Negative Interest Rate Policy and the Influence of Macroeconomic News on Yields
}

Rasmus Fatum, Naoko Hara and Yohei Yamamoto

\section{Globalization Institute Working Paper 354}

Research Department

https://doi.org/10.24149/gwp354

Working papers from the Federal Reserve Bank of Dallas are preliminary drafts circulated for professional comment. The views in this paper are those of the authors and do not necessarily reflect the views of the Federal Reserve Bank of Dallas or the Federal Reserve System. Any errors or omissions are the responsibility of the authors. 


\title{
Negative Interest Rate Policy and the Influence of Macroeconomic News on Yields*
}

\author{
Rasmus Fatum $^{\dagger}$, Naoko Hara ${ }^{\ddagger}$ and Yohei Yamamoto ${ }^{\S}$
}

January 27,2019

\begin{abstract}
We consider the influence of domestic and US macroeconomic news surprises on daily bond yields over the January 1999 to January 2018 period for four advanced Negative Interest Rate Policy (NIRP) economies - Germany, Japan, Sweden, and Switzerland. Our results suggest that the influence of macroeconomic news surprises is for all four countries under study during the NIRP period non-existent or noticeably weaker than during the preceding Zero Interest Rate Policy (ZIRP) period. Our results are consistent with the suggestion that NIRP is characterized by a lower bound that is no less constraining than the zero lower bound that characterizes ZIRP.
\end{abstract}

Keywords: NIRP, Bond Yields, Macroeconomic News

JEL Classifications: E43; E52; E58

\footnotetext{
*This research was carried out in part while Fatum was Visiting Scholar at the Bank of Japan's Institute for Monetary and Economic Studies (IMES). Fatum is grateful to colleagues at the IMES for their hospitality and for helpful discussions. Fatum acknowledges financial support from a Foote Professorship in International Business and an EFF-SAS award. Yamamoto acknowledges financial support from MEXT Grant-in-Aid for Scientific Research No. 17H00985. We thank Mototsugu Shintani, Etsuro Shioji, Carl Walsh and Jing Cynthia Wu for helpful comments and Jens Iversen for help with the Swedish yield data. The views expressed in this paper do not necessarily reflect the views of the Bank of Japan, Federal Reserve Bank of Dallas or the Federal Reserve System.

${ }^{\dagger}$ Corresponding author: Rasmus Fatum, School of Business, University of Alberta, Edmonton, Alberta, Canada T6G 2R6, rasmus.fatum@ualberta.ca. Fatum is also a Research Associate at the Federal Reserve Bank of Dallas and member of the Economic Policy Research Unit (EPRU) at the University of Copenhagen.

${ }^{\ddagger}$ Naoko Hara, Institute for Monetary and Economic Studies, Bank of Japan, 2-1-1 Nihonbashi-Hongokucho, Tokyo 1038660, Japan, naoko.hara@boj.or.jp.

$\S$ Yohei Yamamoto, Department of Economics, Hitotsubashi University, 2-1 Naka, Kunitachi, Tokyo 186-8601, Japan, yohei.yamamoto@econ.hit-u.ac.jp.
} 


\section{Introduction}

We investigate the effects of domestic and US macroeconomic news surprises on bond yields over the January 1999 to January 2018 period for four advanced negative interest rate policy (NIRP) economies - Germany, Japan, Sweden, and Switzerland. We focus on the possibility of time-variation in the influence of news surprises coinciding with changes in the country-specific domestic monetary policy stance.

Recent contributions by Swanson and Williams (2014a,b) suggest that the influence of macroeconomic news on bond yields varies with the monetary policy stance. ${ }^{1}$ Specifically, Swanson and Williams (2014a,b) compare the sensitivity of yields to news surprises when the monetary policy stance is conventional, i.e. when interest rates are above zero or above ultra-low levels, to when monetary policy is constrained by the zero lower bound or characterized by ultra-low rates. They find that yields respond less to news surprises during the latter policy regime and suggest that the extent to which yields respond to news is indicative of the extent to which monetary policy is constrained.

Taking our cue from Swanson and Williams (2014a,b), our research objective is two-fold. First, we attempt to shed light on whether the influence of news is different during the NIRP period compared to during the preceding zero interest rate policy (ZIRP) period. Second, in doing so we seek to provide insights on whether the NIRP regime can be considered more or less constraining than the zero-lower bound associated with the preceding ZIRP regime. In addressing the first part of our research objective we attempt to

\footnotetext{
${ }^{1}$ The vast literature and interest in whether macroeconomic news influence asset prices and whether the influence is time-varying is not surprising considering that macroeconomic news help explain a nonnegligible share of the daily variation in asset prices. For example, Altavilla et al. (2017) find that macro news explain about $10 \%$ of daily variation in bond yields while Evans and Lyons (2008) suggest that macro news explain more than $30 \%$ of daily exchange rate variation.
} 
make a specific contribution to the literature on macro news and asset prices while addressing the second part of our research question allows us to attempt to contribute to our understanding of NIRP and the lower bound constraint associated with NIRP. ${ }^{2}$

To facilitate our investigation we employ a data set of interest rate series consisting of daily zero-coupon government bond yields with medium- and longer-term maturities ranging from 1 to 10 years in conjunction with a comprehensive set of date-stamped United Stated (US) and non-US macroeconomic announcements and preceding survey expectations. Our full sample spans the 1 January 1999 to 31 January 2018 period.

Our empirical analysis of the time-varying effects of macro news surprises on bond yields follows the two-step procedure described in Swanson and Williams (2014a,b). We consider for each country three different monetary policy regimes (conventional, ZIRP and NIRP) and we choose for each country the first regime as our normalization sub-sample. While our focus is on daily frequency estimations we also carry out our empirical analysis using monthly frequency series. To provide additional insights we also investigate the effect of macroeconomic news surprises on the yield curve.

Overall, our results suggest that the influence of macroeconomic news surprises is for all four countries either noticeably weaker or non-existent during the NIRP period than during the preceding ZIRP period. This is an important finding as it indicates that bond yields in NIRP countries are less hinged on fundamentals compared to during normal or ZIRP regimes. Furthermore, it is a finding that is at a minimum consistent with the

\footnotetext{
${ }^{2}$ Whether monetary policy during NIRP is more or less constrained than during ZIRP is not immediately obvious. By construction, NIRP is associated with an accommodative monetary policy beyond what the zero lower bound and the ZIRP would permit. However, as we argue in Section 2.1, a lower bound exists also for NIRP countries although unlike the zero lower bound the exact position of the lower bound on the negative scale is unknown and possibly time-varying.
} 
suggestion that NIRP is associated with a lower bound that is no less constraining than the ZIRP lower bound.

We extend our analysis and check the robustness of our baseline results by considering the possibility of asymmetric effects of good versus bad news and by addressing whether the distribution of news appears to vary systematically across the three different monetary policy regimes under study. We also assess separately the effects of domestic (non-US) news, and we control for key US monetary policy announcement dates. To further check the robustness of our fixed-window regression results we also compute the sequence of coefficient estimates from one-year rolling windows. Moreover, we compare our results to the context of an economy that maintained ultra-low interest rates during the time-period when the countries considered in our baseline analysis pursued NIRP regimes by extending our analysis to consider the effects of macroeconomic news on yields for the case of United Kingdom (UK).

The rest of the paper is organized as follows. Section 2 describes institutional aspects and characteristics of NIRP. Sections 3 and 4 detail our data and empirical methodology, respectively. Section 5 presents our results. Section 6 provides extensions and robustness checks. Section 7 concludes.

\section{Institutional Aspects and Characteristics of NIRP}

The unprecedented era of major central banks pursuing negative interest rate policies began June 11, 2014, when the European Central Bank (ECB) deposit rate was lowered to -0.10 percent. Subsequently, on February 16, 2016, the second major central bank, the Bank of 
Japan, lowered its deposit rate to -0.10 percent. ${ }^{3}$ Between the introduction of NIRP by the ECB and the Bank of Japan, Switzerland and Sweden also went from ultra-low to negative interest rates, and both did so around the same time. Switzerland lowered its deposit rate (the so-called "sight deposit rate") to - 0.75 percent on January 15, 2015, while Sweden lowered its policy rate, the repo rate, to -0.10 percent on February 12, $2015 .{ }^{4}$ The salient and common policy objective of NIRP for all four countries under study is to counter deflationary pressures and raise inflation. For Switzerland, the stated objective of NIRP is dual in that the policy also aims to reduce or prevent domestic currency appreciation pressures in order to avoid a stifling of economic growth.

Denmark is the first advanced economy to enter NIRP territory as Denmark lowered its certificate of deposit rate to -0.20 percent as early as July 5, 2012. However, because the objective of the Danish NIRP pertains to maintenance of the DKK vis-à-vis the EUR within the Exchange Rate Mechanism (ERM) II framework, the context and circumstance of the Danish NIRP are very different from those of the countries under study. For this reason, we do not include Denmark in our sample. Furthermore, Bulgaria and Hungary introduced negative policy rates on November 26, 2015, and March 22, 2016, respectively. Neither Bulgaria nor Hungary is considered in our analysis as both countries are generally classified as emerging market economies and thus very different from the advanced economies under study.

\footnotetext{
${ }^{3}$ Prior to the introduction of the Japanese NIRP, the ECB deposit rate had been further lowered and was at the time of Japan entering NIRP held at -0.30 percent. Shortly after the Bank of Japan announcement of NIRP the ECB on March 16, 2016, reduced its deposit rate to -0.40 percent. See Wu and Xia (2008) for details on the ECB NIRP rate cuts and a careful analysis of their impact on the yield curve.

${ }^{4}$ The Swedish deposit rate entered negative territory, at -0.50 percent, on June 7, 2014.
} 
For additional details on advanced economy NIRP countries, and some early assessments of the successfulness of NIRP, see ADBI (2016) and IMF (2017).

\section{$2.1 \quad$ Characteristics of NIRP}

The move from ZIRP or ultra-low interest rates to NIRP marks at least a nominally dramatic shift in monetary policy. However, two essential aspects associated with the ZIRP regime also characterize the NIRP regime. First, while the emergence of NIRP has certainly proven that the lower bound is not binding at zero, or at above-zero but ultra-low interest rates, a binding lower bound nevertheless remains. This is, simply, because negative interest rates are only meaningful when these are above or equate the cost of holding money. ${ }^{5}$ Thus, a lower bound exists also for NIRP countries. Since the cost of holding money is not directly observable and, furthermore, central banks may be reluctant to lower interest rates to the point of testing the cost of holding money, the exact position of the lower bound on the negative scale is unknown. Consequently, the binding lower bound during NIRP is a latent lower bound (LLB).

Second, as shown by Reifschneider and Williams (2000), monetary policy can be effective even if policy rates are at the lower bound constraint by influencing current expectations about the path of future monetary policy when economic conditions and thus policies are such that the constraint is no longer binding. While the context of Reifschneider and Williams (2000) is that of low inflation and low interest rates rather than that of deflationary pressure and NIRP regimes, the basic argument is the same during NIRP in that monetary policy can still be effective in the face of currently binding constraints by

\footnotetext{
${ }^{5}$ Dong and Wen (2017) note that how far in the negative interest rates can go depends on the cost to the private sector of holding money.
} 
altering expectations about, in our context, post-NIRP policies. ${ }^{6}$ Thus, two essential characteristics associated with ZIRP, namely that monetary policy is constrained by an interest rate floor and that monetary policy can nevertheless still be effective, are also essential characteristics of the NIRP regime.

These two essential characteristics of NIRP can be formalized using the illustrative model of Swanson and Williams (2014a). In their model, which is nested in the New Keynesian framework proposed by Clarida, Gali and Gertler (1999) and Woodford (2003) and others, the effect on the economy of the current short-term interest rate being constrained (at the lower bound) may be insubstantial if expectations of the path of future short-term interest rates are unconstrained. We assume, as in Swanson and Williams (2014a), that the central bank follows a Taylor-type rule (Taylor 1993) when setting its short-term interest rate and, furthermore, that the interest rate decision is subject to the constraint that interest rates cannot go below the LLB.

In this model, the short-term interest rate $i_{t}$ is described as follows:

$$
i_{t}=\max \left\{i_{t}^{d}, i_{t}^{*}\right\}
$$

where $i_{t}^{d}$ is the deposit rate and the lower bound. ${ }^{7}$ The term $i_{t}^{*}$ is the "optimal” short-term policy rate determined by the Taylor rule such that:

$$
i_{t}^{*}=\pi_{t}+r_{t}^{*}+a\left(\pi_{t}-\pi\right)+b \hat{y}_{t}
$$

\footnotetext{
${ }^{6}$ As discussed in Swanson and Williams (2014a), this is consistent with the empirical evidence of Gürkaynak, Sack, and Swanson (2005) that show US monetary policy announcements to be mainly effective through the altering of market expectations regarding future monetary policy rather than through changes in the contemporaneous federal funds rate.

${ }^{7} \mathrm{Wu}$ and Xia (2018) state that in the context of the ECB the deposit rate is by definition the lower bound of the Euro Over Night Index Average (EONIA).
} 
where $\pi_{t}$ is the inflation rate, $r_{t}^{*}$ is the natural rate of interest, $\pi$ is the central bank inflation target, $\hat{y}_{t}$ is the output gap, and $a$ and $b$ are non-zero constants that sum to one. ${ }^{8}$ Thus, Equations (1) and (2) encompass the special case in which $i_{t}^{d}=0$ for all $t$ (as described in Swanson and Williams, 2014a).

Equation (1) implies that the daily "change" in the short-term interest rate is

$$
\Delta i_{t}= \begin{cases}\Delta i_{t}^{d} & \text { if } i_{t}^{*} \leq i_{t}^{d} \text { and } i_{t-1}^{*} \leq i_{t-1}^{d} \\ \Delta i_{t}^{*} & \text { if } i_{t}^{*}>i_{t}^{d} \text { and } i_{t-1}^{*}>i_{t-1}^{d} \\ i_{t}^{d}-i_{t-1}^{*} & \text { if } i_{t}^{*} \leq i_{t}^{d} \text { and } i_{t-1}^{*}>i_{t-1}^{d} \\ i_{t}^{*}-i_{t-1}^{d} & \text { if } i_{t}^{*}>i_{t}^{d} \text { and } i_{t-1}^{*} \leq i_{t-1}^{d}\end{cases}
$$

An important implication of Equation (3) is in the first case, suggesting that the change of the short-term interest rate does not directly reflect economic fundamentals through the standard Taylor rule if the optimal rate stays below the deposit rate for both periods, but it does so only through the change of the lower bound $\Delta i_{t}^{d}$.

Following Swanson and Williams (2014a), and regardless of whether current shortterm interest rates are at the lower bound, at zero, or above, medium- and long-term interest rates are determined by current expectations of the path of future short-term nominal interest rates and the term premium such that the M-period yield to maturity on a zerocoupon nominal bond is described as follows:

$$
i_{t}^{M}=\sum_{j=0}^{M-1} E_{t}\left(i_{t+j}\right)+\phi^{M}
$$

where $E_{t}$ is the expectations operator at time $t$ and $\phi^{M}$ is a term premium.

The LLB is then described as:

$$
L L B_{t}^{M}=\sum_{j=0}^{M-1} E_{t}\left(i_{t+j}^{d}\right)+\phi^{M}
$$

\footnotetext{
${ }^{8}$ Hence, $i_{t}^{*}$ corresponds to the "shadow rate" (Black, 1995, and Wu and Xia, 2016).
} 
such that $i_{t}^{M} \geq L L B_{t}^{M}$ always holds by construction of Equation (1). Intuitively, the LLB can thus be interpreted as the cost of holding cash for the next $M-1$ periods as LLB is the sum of future deposit rates plus term premium.

Equation (4) implies that:

$$
\Delta i_{t}^{M}=\sum_{j=0}^{M-1} E_{t}\left(i_{t+j}\right)-\sum_{j=0}^{M-1} E_{t-1}\left(i_{t+j-1}\right)
$$

or, in words, that the daily change in the M-period yield to maturity is given by the change in the expected future path of the short-term interest rate from time $t-1$ to $t$.

Combining Equations (3) and (6) illustrates the following. If the optimal short-term interest rate is expected to stay below the deposit rate for the next $M-1$ periods, then $E_{t}\left(i_{t+j}\right)=E_{t}\left(i_{t+j}^{d}\right)$ and $E_{t-1}\left(i_{t+j-1}\right)=E_{t-1}\left(i_{t+j-1}^{d}\right)$ for $j=0, \ldots, M-1$ and the change in the medium- and long-term interest rates reduces to the change in the expected future deposit rates. Thus, consistent with Equation (3), if the optimal short-term interest rate is expected to stay below the deposit rate for the next $M-1$ periods, the change in neither medium- nor long-term interest rates is directly reflective of economic fundamentals via the Taylor rule but rather via only the deposit rate.

As discussed in Swanson and Williams (2014a,b), the responsiveness of yields to macroeconomic news may indicate the extent to which monetary policy is constrained because macroeconomic news in normal economic circumstances can elicit an off-setting policy response, e.g. a negative GDP announcement can prompt a more accommodative monetary policy stance. Because of the existence of the LLB it is not necessarily the case that the move from ZIRP to NIRP marks a relaxation of a binding constraint. Since the LLB is unobservable, current negative interest rates may already be at the LLB or, if they are not, each additional interest rate decrease, if any, will either reach the LLB or move 
rates further towards the LLB. The implications for the effects of macroeconomic news on yields, therefore, is not that NIRP returns responsiveness of yields to news back to normal. Instead, if monetary policy during NIRP is even more constrained than during ZIRP, the effects of macroeconomic news will be further subdued.

\section{Data}

Our news data consists of a comprehensive set of date-stamped US and non-US macroeconomic announcements and preceding survey expectations. ${ }^{9}$ Our full sample spans the 1 January 1999 to 31 January 2018 period. ${ }^{10}$ We consider news variables that other studies typically find to be important and, as detailed in Table 2, our news data covers five news series for Germany, seven news series for Sweden, five news series for Switzerland, and nine news series for Japan. In addition, we include in our analysis nine news series for the US. The US news series are included in all our baseline estimations, i.e. for each country we consider the effects of the domestic news pertaining to the country in question alongside the effects of the US news.

Our data on survey expectations is obtained from Money Market Services (MMS) provided by Haver Analytics and from Bloomberg News Service. Following the literature (e.g. Andersen et al. 2003, 2007), we construct for each news variable the standardized

\footnotetext{
${ }^{9}$ Fatum and Scholnick (2008) show that failure to disentangle the expected component of news may lead to an underestimation of the impact of news.

${ }^{10}$ Table 1 displays the country-specific monetary policy regime change dates. For the case of Japan, while the beginning of the ZIRP period coincides with the beginning of our full sample period, we refer to the period preceding the introduction of the Japanese quantitative easing (QE) as characterized by conventional monetary policy and the period from the beginning of the Japanese QE to the introduction of the Japanese quantitative and qualitative easing (QQE) as characterized by ZIRP.
} 
news surprise as the unexpected component of the announcement divided by the associated sample standard deviation. ${ }^{11}$

When constructing the news data set for each country we carefully account for the difference in timing across US and domestic macroeconomic announcements.

Our interest rate data series consist of daily zero-coupon government bond yields with medium- and longer-term maturities ranging from 1 to 10 years. German, Japanese, and Swiss yields are available from Deutsche Bundesbank, the Japanese Ministry of Finance, and the Swiss National Bank, respectively. Swedish yields are provided by Sveriges Riksbank. Figure 1 shows the evolution of the yields over the full sample.

\section{Empirical Methodology}

To assess the same-day effects of macroeconomic news surprises on government bond yields we first estimate the following baseline regression model:

$$
\Delta y_{t}=\alpha+x_{t}^{\prime} \beta+\varepsilon_{t}
$$

where $\Delta y_{t}=y_{t}-y_{t-1}$ is the one-day change of a given bond yield, $x_{t}$ is a $K \times 1$ vector of news surprise components associated with the country-specific $K$ different macroeconomic surprises augmented by the inclusion of US macroeconomic surprises. ${ }^{12}$ For a given news variable an entry in vector $x_{t}$ takes on the value of the surprise component on day $t$ when a macroeconomic news announcement is released for this particular variable

\footnotetext{
${ }^{11}$ Let $A_{t}$ denote the value of a given news variable announcement on day $t$. Let $E_{t}$ refer to the median value of the preceding market expectations, and let $\hat{\sigma}$ denote the sample standard deviation of all the surprise components associated with this indicator using the entire sample period. The standardized surprise of the macroeconomic fundamental announced on day $t$ is then defined as $\frac{A_{t}-E_{t}}{\widehat{\sigma}}$.

${ }^{12}$ For example, in the case of Germany $K=14$ as the five German news variables are considered alongside the nine US news variables.
} 
and zero otherwise. The $K \times 1$ coefficient vector $\beta$ captures the sensitivity of a given bond yield to the individual news surprise. The error term $\varepsilon_{t}$ is mean zero.

A possible concern pertaining to our linear model specification is the implicit symmetry assumption with respect to the responsiveness of our dependent variable to good and bad news. When monetary policy rates are constrained, whether by the zero lower bound or by the LLB, monetary policy may not respond to off-set bad news by moving in the negative direction as much as they would to off-set good news by moving in the positive direction for good and bad news surprises of comparable absolute magnitude. In the presence of such policy rate asymmetry, the responsiveness of bond rates to news surprises could be similarly asymmetric. This is a concern in our context because longer-term yields, our dependent variable, are, as discussed earlier, considered an average of expected future short-term rates. However, as argued by Swanson and Williams (2014a,b), when the shortterm interest rate $i_{t}$ is constrained, and policymakers would prefer to substantially further reduce and maintain $i_{t}$ below the constraining bound, in such a situation, the short-term rate becomes completely unresponsive in both positive and negative directions as long as positive news surprises are not so substantial that they bring short-term rates above the binding constraint and cause the economy to exit the binding regime. In other words, if the lower bound is strongly binding the one-sided constraint effectively becomes symmetrically binding. ${ }^{13}$

Estimating the model described in Equation (7) provides us with detailed information on the influence of news surprises on bond yields. However, since the individual news variables included in $x_{t}$ are released only once a month or once a quarter,

\footnotetext{
${ }^{13}$ We extend our framework to formally consider asymmetries in Section 6.
} 
estimating the effects of news using relatively sparse regressors may provide only imprecise estimates. This concern is amplified when addressing the possibility of systematic time variations in the estimated coefficients. Hence, we decompose the coefficients in (7) following Swanson and Williams (2014a,b) such that

$$
\Delta y_{t}=\gamma_{\tau}+x_{t}^{\prime} \beta \delta_{\tau}+\varepsilon_{t}
$$

where $\gamma_{\tau}$ and $\delta_{\tau}$ are scalars. ${ }^{14}$ These scalars are potentially time varying. In particular and with respect to time variation, we consider separately and country by country sub-samples identified according to monetary policy regimes $\tau$ as defined by their respective and country-specific regime change dates. We consider for each country three monetary policy regimes and denote these the conventional monetary policy (CMP) regime, the ZIRP regime, and the NIRP regime, respectively. We address the identification problem with respect to $\beta$ and $\delta_{\tau}$ by imposing for each country that $\delta_{\tau}=1$ during the CMP regime. We choose the CMP regime as our normalization sub-sample since for each country this regime is associated with the largest sub-sample size.

We then estimate Equation (8) following the two-step estimation procedure of Swanson and Williams (2014a,b). In the first step we estimate Equation (8) using the CMP sub-sample. In the second step we use $\hat{x}_{t} \equiv x_{t}{ }^{\prime} \hat{\beta}$, where $\hat{\beta}$ is the first step estimate, as a proxy for $x_{t}^{\prime} \beta$ in order to estimate $\gamma_{\tau}$ and $\delta_{\tau}$ by OLS with heteroskedasticity robust standard errors. ${ }^{15}$ If $\delta_{\tau}$ is less than one in the second (ZIRP) or the third (NIRP) sub-sample, this then indicates that overall the sensitivity of a given bond yield to news surprises has

\footnotetext{
${ }^{14}$ In other words, rather than focusing on the effects of individual news surprises on bond yields, we consider the effects news using for each country a single country-specific index variable that encompasses all countryspecific and US news surprises described in our news data set.

${ }^{15}$ We include observations when all the elements in $x_{t}$ are zero, following the literature. However, the results are qualitatively the same if no-announcement days are excluded.
} 
declined relative to the first (CMP) sub-sample. This approach allows us to similarly compare the estimate of $\delta_{\tau}$ across any two regimes, e.g. ZIRP versus NIRP, to assess whether the overall sensitivity to news surprises has increased or decreased. ${ }^{16}$

The model described in Equation (8) is estimated separately for each NIRP country considered (Germany, Sweden, Switzerland, and Japan) across the full sample period as well as separately across each (country-specific) CMP, ZIRP, and NIRP regime sub-sample period. All our estimations are carried out using government bond yields pertaining to 1year, 2-year, and 10-year maturities.

The two-step procedure has two important advantages. First, the overall time variation of the effects of news surprises is captured by $\delta_{\tau}$ under the assumption that the relative magnitudes of the effects of individual news surprises $\beta$ are time invariant. Second, the overall significance of the effects of news surprises is also assessed by testing for the null hypothesis $H_{0}: \delta_{\tau}=0$ against the alternative hypothesis $H_{1}: \delta_{\tau} \neq 0$ in the second step.

While our main focus is on daily frequency analysis we also implement the twostep procedure using the monthly average of $y_{t}$ and $\hat{x}_{t}$ to assess what Altavilla et al. (2017) refer to as the persistence effect of the macroeconomic news surprises on bond yields. ${ }^{17}$

To provide additional insights we also investigate the effect of macroeconomic news surprises on the yield curve. We use a simple approach in which we extract the first three principal components from our yield curve data set. ${ }^{18}$ More specifically, we do as

\footnotetext{
${ }^{16}$ Swanson and Williams (2014a,b) estimate $\delta_{\tau}$ using 1-year rolling windows. In order to focus on the effects of news separately across different monetary policy regimes we estimate $\delta_{\tau}$ using fixed windows defined according to monetary policy regime change dates. Compared to Swanson and Williams (2014a,b), our results are akin to "snapshots" across different samples of varying lengths.

${ }^{17}$ Altavilla et al. (2017) find evidence that the explanatory power of news surprises with respect to the variation in bond yields increases when their model is estimated using data at a lower frequency.

${ }^{18}$ See Inoue and Rossi (2018a,b) for recent contributions to yield curve modelling and its application to monetary policy analysis.
} 
follows. First, let $z=\left[z_{1}{ }^{\prime}, \cdots, z_{T}{ }^{\prime}\right]^{\prime}$ be a $T \times 3$ eigenvector matrix of a $T \times T$ matrix $\left(y y^{\prime}\right)$. Let $y=\left[y_{1}{ }^{\prime}, \cdots, y_{T}{ }^{\prime}\right]^{\prime}$ be a $T \times 10$ matrix of yields with $y_{t}=\left[y_{t}^{1 \prime}, \cdots, y_{t}^{10}\right]$ being a $10 \times 1$ vector of yields. The upper subscript denotes the maturity (year). Second, we then reestimate our baseline model described by Equation (4) one at a time for each element in $z_{t}$ as our new dependent variable in place of the dependent variable $y_{t}$. We follow Litterman and Sheinkman (1991) and Ang and Piazzesi (2003) and others in labeling the three elements in $z_{t}$ as the level, the slope, and the curvature components.

\section{5. $\quad$ Results}

Table 3 shows the results of estimating Equation (8) country by country and separately across the full and the three monetary policy regime defined sub-samples using daily data. These are our baseline results. As our full sample results suggest, news surprises systematically influence bond yields for all four countries when we consider the 1999 to 2018 period as a whole. The magnitude and significance of the news index coefficient estimates pertaining to the ZIRP sub-sample period suggest that yields are influenced by macro news surprises during this period as well but generally less so or, in the case of Japan, not at all. These results are consistent with the findings of Swanson and Williams (2014b) in that the sensitivity of yields to news surprises remains significant during ZIRP for Germany. Moreover, the news index coefficient estimate remains strongly significant during the ZIRP period for all countries but Japan. Most importantly, and directly addressing our research question, our baseline results clearly suggest that the influence of macroeconomic news surprises is for all countries either noticeably weaker or non-existent during the NIRP period. This is an important finding. It indicates that bond yields in NIRP 
countries are essentially less hinged on fundamentals and, furthermore, it is at least consistent with the suggestion that the LLB associated with ZIRP is no less constraining than the ZIRP lower bound.

Table 4 reports the results of the monthly frequency estimations. As the table shows, for the full sample our monthly frequency results are very similar to the daily frequency results reported in Table 3. Consistent with Altavilla et al. (2017), when comparing the overall explanatory power of the news surprises we generally find that the effects of news surprises on yields is persistent in the sense that the $R^{2}$ is larger when the monthly frequency data is used to capture the variations in yields. In contrast with the daily frequency estimation results, we find at most only marginally significant news index coefficient estimates across the ZIRP sub-sample when considering monthly frequency data. We find no monthly frequency effects of news surprises during NIRP for either of the four countries under study. Unsurprisingly, considering that we do not find any news surprise coefficient estimates to be significant at conventional levels when analyzing monthly frequency data, the explanatory power of news as measured by $R^{2}$ has declined from the CMP period to the NIRP period.

Turning to the yield curve analysis characterized by the three principal components, Table 5 reports our results. As the table shows, when we consider the full sample period, all the three components of the yield curve are strongly sensitive to the macro news surprises in all four NIRP countries. This finding is consistent with the suggestion that news surprises can affect the shape of the yield curve by influencing the expectation of the future path of the short-term interest rate. Not surprisingly, considering that there is a wide consensus that the first few principal components capture almost all the variation in the 
term structure (e.g. Duffee, 2013), we find that in case of each of the four NIRP countries the first three principal components explain more than $95 \%$ of the total variation of

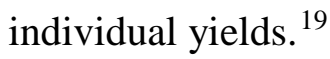

Consistent with our baseline results as well as with our monthly data findings, the principal component analysis pertaining to the NIRP sub-sample indicates that the sensitivity to news surprises is not statistically significant at conventional levels for neither one of the three yield curve components for any of the four NIRP countries under study with the exception of the first principal component for Sweden. ${ }^{20}$

\section{Extensions and Robustness}

In this section we extend our analysis and check the robustness of our main results by considering the possibility of asymmetric effects of good versus bad news, by addressing whether the distribution of news appears to differ across sub-samples, by assessing separately the effects of domestic (non-US) news, by controlling for key US large scale asset purchase (LSAP) announcements, and by estimating rolling regressions. To compare our results to the context of an economy that maintained ultra-low interest rates during the time-period when the countries considered in our baseline analysis pursued NIRP regimes we also extend our analysis to consider the effects of macroeconomic news on yields for the case of UK. ${ }^{21}$

\footnotetext{
${ }^{19}$ Results pertaining to the explanatory power of the first three components with respect to total variation of individual yields are not shown for brevity but available from the authors upon request.

${ }^{20}$ We also carried out the principal components investigation using monthly frequency estimations. The components analysis using monthly frequency data yields results similar to the daily data results reported in Table 5 and are not included for brevity but available from the authors upon request.

${ }^{21}$ For brevity, only results pertaining to the UK are reported. All other extension and robustness results are available upon request.
} 
First, we consider the possibility that good news might influence bond yields differently than bad news and the possibility that such differences might be sub-sample specific, i.e. we consider for each of the countries in our sample possible good news versus bad news asymmetries separately across the CMP, the ZIRP, and the NIRP regimes. This is a particularly important consideration as it pertains to the validity of our linear specification especially during the ZIRP and the NIRP periods, as discussed in Section 3. Moreover, while most studies tend to find mostly sparse empirical evidence in support of good versus bad news asymmetries some studies find some, albeit mostly limited, support for the suggestion that such asymmetries manifest across different stages of the business cycle (see, for example, Andersen et al., 2007, on the effects of news in bond and other markets as well as, for example, Andersen et al., 2003, on the effects of news in foreign exchange markets). ${ }^{22}$ As it turns out, while we find some differences in coefficient estimates when comparing the influence of good and bad news on yields across the full sample as well as separately across the monetary policy regimes, these differences are not significant and do not point to a systematic pattern for any of the countries considered. Thus, while our investigation of asymmetries confirms the robustness of our main findings we do not find evidence of systematically different effects of good versus bad news.

Second, to address the possibility that what appears to be a systematic change in the responsiveness of yields to news across different monetary policy regimes might be the consequence of an underlying systematic change in the distribution of news across said regimes we follow Swanson and Williams (2014a,b) and plot the distribution of the news index variable country by country and separately across the full sample and across each of

\footnotetext{
${ }^{22}$ While our sub-samples are defined according to the stance of monetary policy stance rather than the stage of the business cycle, the former is at a minimum influenced by the latter.
} 
the three policy regime defined sub-samples. Similar to the plots of US nonfarm payrolls surprises and US Core CPI surprises pre- and post-GFC documented in Swanson and Williams (2014a,b), our news index variable distribution plots are country by country similar across the CMP, the ZIRP, and the NIRP sample periods, thereby offering no support for the suggestion that the change in the relative effect of news across the three periods can be explained by changes in the distribution of news, i.e. changes in the news variable itself.

Third, we redo our baseline analysis with only non-US news included as explanatory variables, i.e. for each country we now consider only the influence on the yields of the country in question of the domestic news from this particular country. When doing so we find that for the full sample, domestic news matter for domestic bond yields for all but Switzerland. For Germany and Sweden we find that domestic news matter less or not at all for respective domestic bond yields during the NIRP regime relative to during the ZIRP regime. Only for Japan do we find that domestic news do not matter at all for domestic bond yields during neither the NIRP nor the ZIRP regime. ${ }^{23}$ Overall, our domestic news only results are generally consistent with the previously discussed baseline findings.

Fourth, we extend the analysis to take into account the possibility that US QE monetary policy announcements influence NIRP country bond yields and check whether our previously discussed baseline results are robust to the inclusion of these announcements. To do so we first obtain the dates and associated time-stamps for seven major US QE announcements in order to construct a US-QE dummy variable that takes on

\footnotetext{
${ }^{23}$ The lack of influence of Japanese macro news on Japanese bond yields is consistent with Cheung et al. (2018) and their finding that from the GFC period and onwards the influence of Japanese macro news on the JPY/USD rate has all but disappeared.
} 
the value one when a US QE announcement occurs, and zero otherwise. ${ }^{24}$ In turn, we reestimate our baseline models separately across the full and the three sub-samples (CMP, ZIRP, and NIRP) with the US-QE dummy variable included as an additional explanatory variable.

The results of controlling for US QE announcements suggest that the US-QE dummy variable is mostly insignificant. This is a surprising finding, implying that the US QE announcements are inconsequential to the foreign NIRP bond markets. However, preceding survey expectations pertaining to the unscheduled US QE announcements are unavailable and, therefore, we are unable to control for only the surprise component of these announcements. Consequently, our results pertaining to the coefficient estimates of the US-QE dummy variable are interpreted with much caution. More importantly for our research question at hand, the addition of this US monetary policy news control variable does not in any way change our previously discussed baseline results as the macro news results based on estimations that omit this control are identical to the macro news results based on estimations that include this control. ${ }^{25}$

Fifth, to further check the robustness of our fixed-window regression results we also compute the sequence of coefficient estimates from one-year rolling windows for 1year, 2-year and 10-year yields, respectively. We do so separately for each of the four countries. We follow the same specification as Swanson and Williams (2014a, b) except that our standard errors are computed from the second stage regression only. Similar to

\footnotetext{
${ }^{24}$ See Rosenberg (2015) for details on the seven major US QE announcements dates considered.

${ }^{25}$ For completeness, we also check the robustness of our results with respect to US QE announcements by simply omitting the US announcement dates from our sample. When we re-estimate our models on the reduced sample our baseline results remain unchanged. We also control for non-US monetary policy announcements by omitting non-US announcement dates from our sample separately for each of the relevant NIRP country considered and find our previously discussed results robust to this data change.
} 
Swanson and Williams, our rolling regression results show fluctuations in sensitivity over the CMP period and a general decline in sensitivity during the ZIRP regime, subject to some country heterogeneity. This decline in sensitivity is, on average, further pronounced during the NIRP regime. Overall, our rolling regression results are consistent with our baseline results in that the coefficient estimates generally decline from the CMP period to the ZIRP period and even more so during the NIRP period.

Sixth and final, we extend our analysis to consider the effects of macroeconomic news on yields for the case of UK. Doing so facilitates a comparison of our results to those pertaining to an economy that maintained ultra-low interest rates during the time-period when the countries considered in our baseline analysis pursued NIRP regimes. ${ }^{26}$ We report the results of the UK analysis in Table 6. As the table shows, and broadly consistent with the findings of Swanson and Williams (2014b), we find no systematic and statistically discernible difference between the responsiveness of UK yields to news when comparing our results across the full sample to those pertaining to the ZIRP comparable period (which the UK begins March 2009 and continues throughout the remainder of our full sample period). ${ }^{27}$ Certainly, the results of this extension do not provide direct evidence that NIRP regimes are necessarily associated with less responsiveness of yields to news. However, the fact that we find evidence of a general decline in responsiveness to news when considering NIRP countries, but do not repeat this finding when considering an economy that remained in a ZIRP comparable regime rather than moving into NIRP, is at least

\footnotetext{
${ }^{26}$ UK is also considered, alongside Germany, in Swanson and Williams (2014b). Swanson and Williams (2014b) note that given the interest rate structure of UK rates the UK period of ultra-low interest rates is comparable to ZIRP even though UK policy rates did not reach zero.

27 This finding is broadly consistent with Swanson and Williams (2014b). They report no statically significant evidence that their sensitivity measure of UK yields to news declines during the ZIRP comparable period.
} 
consistent with our baseline results and the suggestion that news are relatively less influential on bond yields during NIRP compared to during ZIRP.

\section{Conclusion}

In this paper we have considered the influence of domestic and US macroeconomic news surprises on bond yields over the January 1999 to January 2018 period for four advanced NIRP economies - Germany, Japan, Sweden, and Switzerland - with focus on the possibility of time-variation in the influence of news coinciding with changes in the domestic monetary policy stance. Specifically, we have separately for each of the four NIRP countries in our sample assessed the influence of news surprises on yields across the full sample period as well as separately across the country-specific CMP, ZIRP, and NIRP periods.

Overall, our results suggest that the influence of macroeconomic news surprises is for all four countries either noticeably weaker or non-existent during the NIRP period when compared to the preceding ZIRP period. This is an important finding. It indicates that bond yields in NIRP countries are essentially less hinged on fundamentals and, furthermore, it is a finding that is at a minimum consistent with the suggestion that the LLB associated with NIRP is no less constraining than the ZIRP lower bound.

It is prudent to stress an important caveat when interpreting our results. By construction, our results do not provide direct evidence that the observed changes in the sensitivity of yields to news surprises is necessarily due to changes in the monetary policy stance. While we find that changes in sensitivity are systematic and coincide with monetary policy regime changes for all four NIRP countries considered, particularly we find that the 
sensitivity of yields to news surprises is reduced during NIRP, these results provide coincidental rather than causal evidence as we are not providing statistical evidence that the reported sensitivity changes are necessarily due to monetary policy regime changes. We are not able to provide such causal evidence in the context of our present empirical framework since our "sample” of monetary policy regimes essentially consists of three data points, i.e. CMP, ZIRP, and NIRP. Moreover, we cannot rule out that other economic factors and events influence how bond yields react to macro news.

Nevertheless, the fact that we find a clear pattern of statistical evidence indicating that the influence of macroeconomic news surprises during NIRP is significantly less pronounced compared to during ZIRP for all four NIRP countries in our sample, alongside the fact that we find that the influence of news surprises on yields did not decrease for the comparison country that did not enter into a NIRP regime, are at a minimum consistent with the suggestion that macroeconomic news affect bond yields less when policy rates are negative. Thus, our results are also at a minimum consistent with the suggestion that monetary policy during NIRP is more rather than less constrained compared to during ZIRP, thereby lending credence to the notion of a constraining LLB as a characteristic of NIRP regimes. 


\section{References}

Altavilla, C., Giannone, D., Modugno, M., 2017. Low frequency effects of macroeconomic news on government bond yields. Journal of Monetary Economics 92, 31-46.

https://doi.org/10.1016/j.jmoneco.2017.08.004

Andersen, T.G., Bollerslev, T., Diebold, F.X.,Vega, C., 2003. Micro effects of macro announcements: real-time price discovery in foreign exchange. American Economic Review 93, 38-62. https://doi.org/10.1257/000282803321455151

Andersen, T.G., Bollerslev, T., Diebold, F.X.,Vega, C., 2007. Real-time price discovery in global stock, bond and foreign exchange markets. Journal of International Economics 73, 251-277. https://doi.org/10.1016/j.jinteco.2007.02.004

Ang, A., Piazzesi, M., 2003. A no-arbitrage vector autoregression of term structure dynamics with macroeconomic and latent variables. Journal of Monetary Economics 50, 745-787. https://doi.org/10.1016/s0304-3932(03)00032-1

Asian Development Bank Institute, 2016. The implications of ultra-low and negative interest rates for Asia. ADBI Conference 2016.

Black, F., 1995. Interest rates as options. Journal of Finance 50, 1371-1376. https://doi.org/10.1111/j.1540-6261.1995.tb05182.x

Cheung, Y.W., Fatum, R., Yamamoto, Y., 2018. The exchange rate effects of macro news during the global financial crisis. Journal of International Money and Finance, in press. https://doi.org/10.1016/j.jimonfin.2018.03.009

Clarida, R., Gali, J., Gertler, M., 1999. The science of monetary policy: A New Keynesian perspective. Journal of Economic Literature 37, 1661-1707. https://doi.org/10.1257/jel.37.4.1661

Dong, F, Wen, Y., 2017. Optimal monetary policy under negative interest rate. Federal Reserve Bank of St. Louis Working Paper 2017-019A. https://doi.org/10.20955/wp.2017.019

Duffee, G., 2013. Forecasting interest rates. Handbook of Forecasting, Chapter 7, p. 385426. https://doi.org/10.1016/b978-0-444-53683-9.00007-4

Evans, M.D.D., Lyons, R.K., 2008. How is macro news transmitted to exchange rates?. Journal of Financial Economics 88, 26-50. https://doi.org/10.1016/j.jfineco.2007.06.001

Fatum, R., Scholnick, B., 2008. Monetary policy news and exchange rate responses: do only surprises matter?. Journal of Banking and Finance 32, 1076-1086. https://doi.org/10.1016/j.jbankfin.2007.09.014 
Gürkaynak, R.S., Sack, B., Swanson, E.T., 2005. Do actions speak louder than words? The response of asset prices to monetary policy actions and statements. International Journal of Central Banking 1, 55-93.

Inoue, A., Rossi, B., 2018a. The Effects of conventional and unconventional monetary policy: A new approach. Working Paper.

Inoue, A., Rossi, B., 2018b. The Effects of conventional and unconventional monetary policy on exchange rates. Working Paper.

International Monetary Fund, 2017. Negative interest rate policies - initial experiences and assessments. IMF Policy Paper, August.

Litterman, R., Scheinkman, J., 1991. Common factors affecting bond returns. Journal of Fixed Income 1, 51-61. https://doi.org/10.3905/jfi.1991.692347

Reifschneider, D., Williams, J.C., 2000. Three lessons for monetary policy in a lowinflation era. Journal of Money, Credit, and Banking 32, 936-966. https://doi.org/10.2307/2601151

Rosenberg, E.S., 2015. Lesson from the US experience with QE. Federal Reserve Bank of Boston.

Swanson, E.T., Williams, J.C., 2014a. Measuring the effect of the zero lower bound on medium- and longer-term interest rates. American Economic Review 104, 3154-3185. https://doi.org/10.1257/aer.104.10.3154

Swanson, E.T., Williams, J.C., 2014b. Measuring the effect of the zero lower bound on yields and exchange rates in the U.K. and Germany. Journal of International Economics 92, 2-21. https://doi.org/10.1016/j.jinteco.2013.11.009

Taylor, J.B., 1993. Discretion versus policy rules in practice. Carnegie-Rochester Conference Series on Public Policy 39, 195-214.

https://doi.org/10.1016/0167-2231(93)90009-l

Woodford, M., 2003. Interest and prices: Foundations of a theory of monetary policy. Princeton University Press.

Wu, J.C., Xia, F.D., 2016. Measuring the macroeconomic impact of monetary policy at the zero lower bound. Journal of Money, Credit and Banking 48, 253-291. https://doi.org/10.1111/jmcb.12300

Wu, J.C., Xia, F.D., 2018. The negative interest rate policy and the yield curve. BIS Working Papers No. 703. 
Figure 1. Yields for NIRP countries
a) Germany
b) Sweden
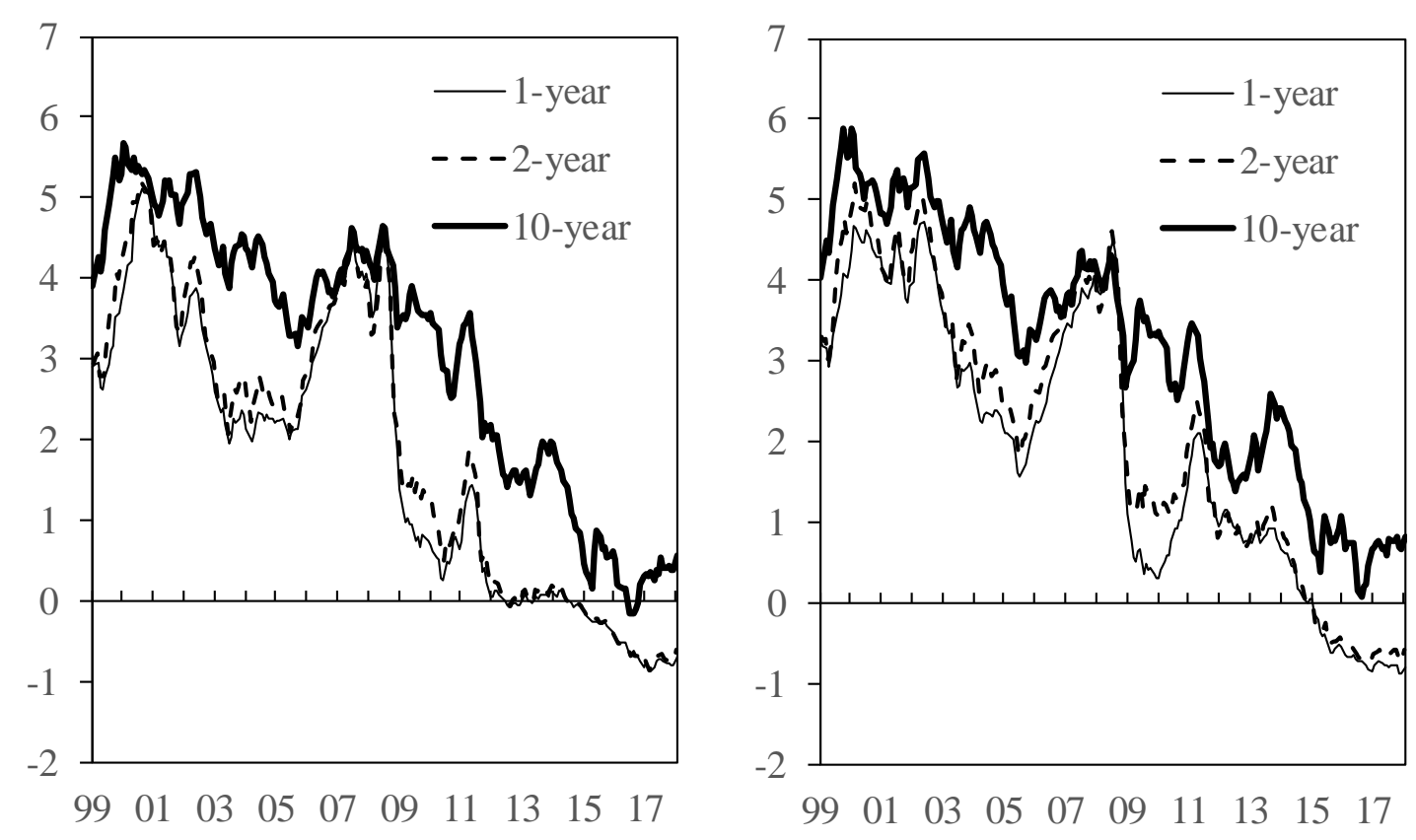

c) Switzerland

d) Japan
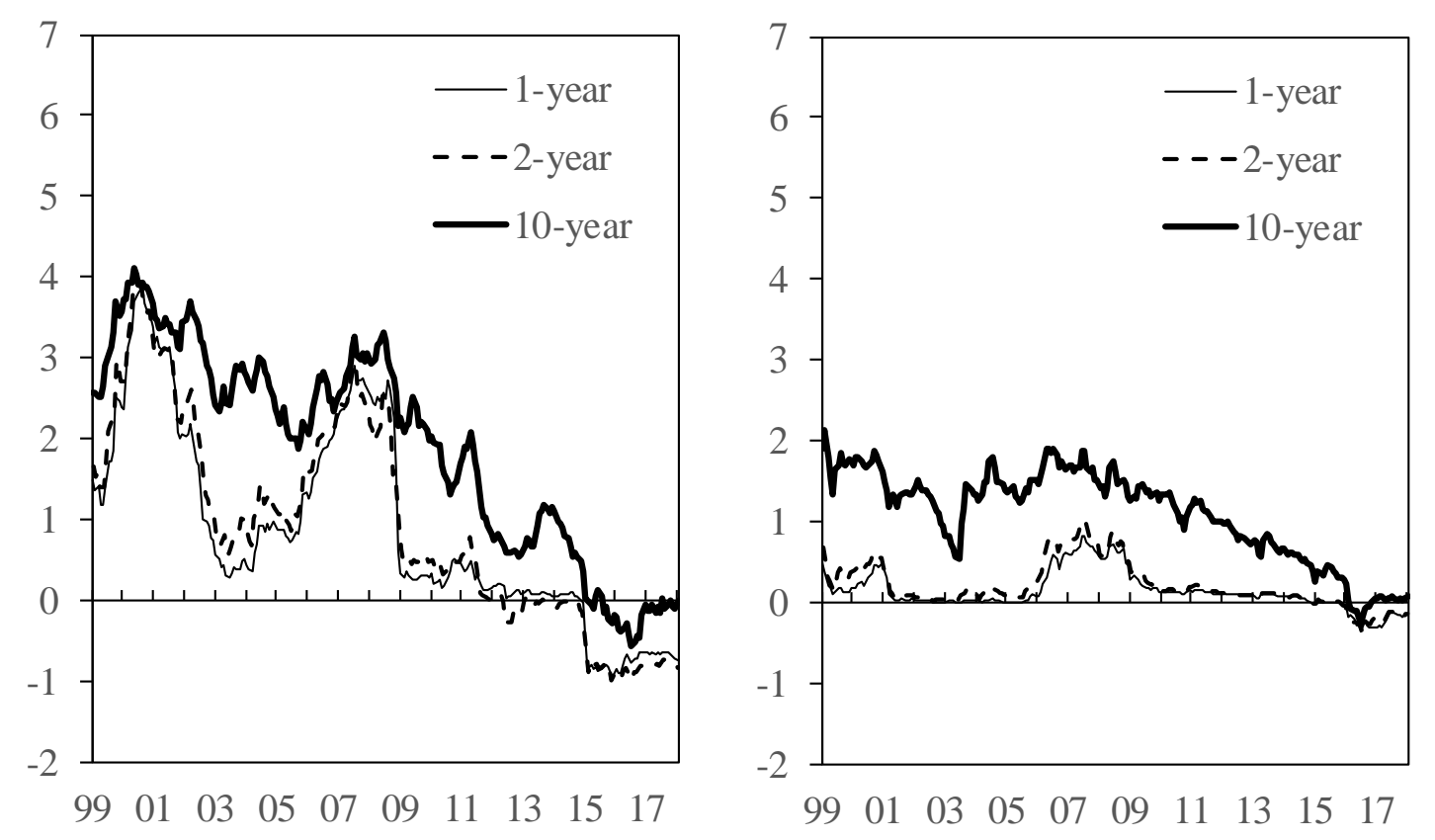
Table 1. Monetary policy regime change dates

\begin{tabular}{lcccc} 
& Germany & Sweden & Switzerland & Japan \\
\hline ZIRP & $10 / 30 / 2008$ & $7 / 13 / 2009$ & $12 / 11 / 2008$ & $4 / 4 / 2013$ \\
NIRP & $6 / 11 / 2014$ & $2 / 18 / 2015$ & $1 / 22 / 2015$ & $2 / 16 / 2016$
\end{tabular}


Table 2. Macroeconomic news

a) Germany

\begin{tabular}{lcccccc} 
& \multicolumn{9}{c}{ Non-zero announcement surprises } & \multirow{2}{*}{ Starting date } & Frequency \\
& Full & Pre-ZIRP & ZIRP & NIRP & & \\
\hline Domestic news & 152 & 75 & 47 & 30 & $1 / 10 / 2000$ & Monthly \\
$\quad$ CPI & 222 & 114 & 65 & 43 & $1 / 21 / 1999$ & Monthly \\
IFO & 218 & 113 & 62 & 43 & $1 / 13 / 1999$ & Monthly \\
Real retail sales & 222 & 115 & 66 & 41 & $1 / 8 / 1999$ & Monthly \\
Unemployment Change & 61 & 30 & 21 & 10 & $2 / 19 / 1999$ & Quarterly \\
Real GDP preliminary & & & & & & \\
US news & 972 & 497 & 288 & 187 & $1 / 7 / 1999$ & Weekly \\
Job claims & 209 & 109 & 61 & 39 & $1 / 15 / 1999$ & Monthly \\
Capacity utilization & 138 & 69 & 40 & 29 & $1 / 14 / 1999$ & Monthly \\
CPI core & 224 & 115 & 67 & 42 & $1 / 4 / 1999$ & Monthly \\
ISM manufacturing & 228 & 117 & 68 & 43 & $1 / 8 / 1999$ & Monthly \\
Nonfarm payrolls & 172 & 90 & 45 & 37 & $1 / 12 / 1999$ & Monthly \\
PPI for final demand & 179 & 82 & 58 & 39 & $6 / 13 / 2001$ & Monthly \\
Retail sales & 163 & 81 & 55 & 27 & $1 / 8 / 1999$ & Monthly \\
Unemployment Rate & 74 & 39 & 20 & 15 & $1 / 29 / 1999$ & Quarterly \\
RGDP advance & & & & & &
\end{tabular}

b) Sweden

\begin{tabular}{lcccccc} 
& \multicolumn{7}{c}{ Non-zero announcement surprises } & Starting date & Frequency \\
& Full & Pre-ZIRP & ZIRP & NIRP & & \\
\hline Domestic news & & & & & & \\
CPI all items & 187 & 104 & 54 & 29 & $1 / 19 / 1999$ & Monthly \\
Industrial production & 198 & 103 & 64 & 31 & $1 / 27 / 1999$ & Monthly \\
Retail sales & 224 & 123 & 66 & 35 & $1 / 20 / 1999$ & Monthly \\
Unemployment Rate & 199 & 114 & 59 & 26 & $1 / 20 / 1999$ & Monthly \\
Trade balance & 132 & 62 & 53 & 17 & $3 / 4 / 1999$ & Monthly \\
PMI & 147 & 50 & 65 & 32 & $12 / 1 / 2004$ & Monthly \\
Real GDP & 72 & 41 & 20 & 11 & $3 / 10 / 1999$ & Quarterly \\
US news & & & & & & \\
Job claims & 972 & 532 & 289 & 151 & $1 / 7 / 1999$ & Weekly \\
Capacity utilization & 209 & 117 & 60 & 32 & $1 / 15 / 1999$ & Monthly \\
CPI core & 138 & 76 & 39 & 23 & $1 / 14 / 1999$ & Monthly \\
ISM manufacturing & 224 & 124 & 66 & 34 & $1 / 4 / 1999$ & Monthly \\
Nonfarm payrolls & 228 & 126 & 67 & 35 & $1 / 8 / 1999$ & Monthly \\
PPI for final demand & 172 & 96 & 44 & 32 & $1 / 12 / 1999$ & Monthly \\
Retail sales & 179 & 90 & 58 & 31 & $6 / 13 / 2001$ & Monthly \\
Unemployment Rate & 163 & 88 & 54 & 21 & $1 / 8 / 1999$ & Monthly \\
RGDP advance & 74 & 42 & 20 & 12 & $1 / 29 / 1999$ & Quarterly
\end{tabular}


Table 2. Macroeconomic news (cont.)

c) Switzerland

\begin{tabular}{lcccccc} 
& \multicolumn{7}{c}{ Non-zero announcement surprises } & Starting date & Frequency \\
& Full & Pre-ZIRP & ZIRP & NIRP & & \\
\hline Domestic news & & & & & & \\
$\quad$ CPI all items & 169 & 88 & 57 & 24 & $2 / 4 / 1999$ & Monthly \\
PMI & 170 & 64 & 72 & 34 & $4 / 1 / 2003$ & Monthly \\
Unemployment rate & 79 & 48 & 24 & 7 & $1 / 7 / 1999$ & Monthly \\
Production \& import prices & 185 & 97 & 59 & 29 & $1 / 15 / 1999$ & Monthly \\
Real GDP preliminary & 61 & 28 & 22 & 11 & $6 / 8 / 2000$ & Quarterly \\
US news & & & & & & \\
Job claims & 972 & 503 & 314 & 155 & $1 / 7 / 1999$ & Weekly \\
Capacity utilization & 209 & 110 & 67 & 32 & $1 / 15 / 1999$ & Monthly \\
CPI core & 138 & 70 & 45 & 23 & $1 / 14 / 1999$ & Monthly \\
ISM manufacturing & 224 & 117 & 72 & 35 & $1 / 4 / 1999$ & Monthly \\
Nonfarm payrolls & 228 & 119 & 73 & 36 & $1 / 8 / 1999$ & Monthly \\
PPI for final demand & 172 & 91 & 49 & 32 & $1 / 12 / 1999$ & Monthly \\
Retail sales & 179 & 83 & 64 & 32 & $6 / 13 / 2001$ & Monthly \\
Unemployment Rate & 163 & 83 & 58 & 22 & $1 / 8 / 1999$ & Monthly \\
RGDP advance & 74 & 40 & 21 & 13 & $1 / 29 / 1999$ & Quarterly
\end{tabular}

d) Japan

\begin{tabular}{|c|c|c|c|c|c|}
\hline \multicolumn{4}{|c|}{ Non-zero announcement surprises } & \multirow{2}{*}{ Starting date } & \multirow{2}{*}{ Frequency } \\
\hline Full & Pre-QQE & QQE-ZIRP & QQE-NIRP & & \\
\hline 122 & 91 & 14 & 17 & $9 / 28 / 2001$ & Monthly \\
\hline 187 & 130 & 33 & 24 & $10 / 29 / 2001$ & Monthly \\
\hline 173 & 117 & 33 & 23 & $4 / 28 / 2003$ & Monthly \\
\hline 215 & 157 & 34 & 24 & $2 / 10 / 2000$ & Monthly \\
\hline 131 & 89 & 26 & 16 & $10 / 14 / 2003$ & Monthly \\
\hline 216 & 158 & 34 & 24 & 11/24/1999 & Monthly \\
\hline 62 & 45 & 10 & 7 & 4/5/1999 & Quarterly \\
\hline 41 & 28 & 8 & 5 & $4 / 1 / 2002$ & Quarterly \\
\hline 48 & 30 & 12 & 6 & $2 / 16 / 2005$ & Quarterly \\
\hline 972 & 723 & 148 & 101 & $1 / 7 / 1999$ & Weekly \\
\hline 209 & 156 & 31 & 22 & $1 / 15 / 1999$ & Monthly \\
\hline 138 & 102 & 20 & 16 & $1 / 14 / 1999$ & Monthly \\
\hline 224 & 168 & 34 & 22 & $1 / 4 / 1999$ & Monthly \\
\hline 228 & 170 & 35 & 23 & $1 / 8 / 1999$ & Monthly \\
\hline 172 & 126 & 24 & 22 & $1 / 12 / 1999$ & Monthly \\
\hline 179 & 128 & 31 & 20 & $6 / 13 / 2001$ & Monthly \\
\hline 163 & 122 & 25 & 16 & 1/8/1999 & Monthly \\
\hline 74 & 55 & 11 & 8 & 1/29/1999 & Quarterly \\
\hline
\end{tabular}


Table 3. Baseline results: Daily frequency

a) Germany

\begin{tabular}{|c|c|c|c|c|c|c|c|c|c|c|}
\hline & 1-year & 2-year & & 10-year & & & 1-year & 2-year & 10-year & \\
\hline$\overline{\text { Full sa }}$ & ple & & & & & $\overline{\text { Full }}$ & pple & & & \\
\hline Index & $0.708^{* * *}$ & 0.714 & $* * *$ & 0.821 * & *** & Index & $0.776^{* * *}$ & $0.858^{* * *}$ & 1.003 * & $* * *$ \\
\hline & $(0.075)$ & $(0.065)$ & & $(0.083)$ & & & $(0.069)$ & $(0.067)$ & $(0.106)$ & \\
\hline R-sq & 0.044 & 0.060 & & 0.044 & & R-sq & 0.066 & 0.085 & 0.046 & \\
\hline$\overline{Z I R P}($ & $0 / 30 / 2008-6 / 1$ & 0/2014) & & & & $\overline{Z I R P(7}$ & $/ 13 / 2009-2 / 17$ & (2015) & & \\
\hline Index & $0.355^{* * *}$ & 0.401 & $* * *$ & 0.647 * & $* * *$ & Index & $0.508^{* * *}$ & $0.685^{* * *}$ & 1.168 & $* * *$ \\
\hline & $(0.123)$ & $(0.121)$ & & $(0.171)$ & & & $(0.108)$ & $(0.127)$ & $(0.268)$ & \\
\hline R-sq & 0.015 & 0.023 & & 0.024 & & -sq & 0.035 & 0.053 & 0.040 & \\
\hline NIRP & $/ 11 / 2014-1 / 3$ & (2018) & & & & NIRP & $/ 18 / 2015-1 / 31$ & /2018) & & \\
\hline Index & 0.072 & 0.057 & & $0.388^{*}$ & ** & Index & $0.321^{* * *}$ & $0.481^{* * *}$ & 0.658 * & \\
\hline & $(0.081)$ & $(0.071)$ & & $(0.191)$ & & & $(0.093)$ & $(0.084)$ & $(0.239)$ & \\
\hline R-sq & 0.002 & 0.001 & & 0.010 & & R-sq & 0.062 & 0.100 & 0.022 & \\
\hline c) Sw & rland & & & & & d) Jap & & & & \\
\hline & 1-year & 2-year & & 10-year & & & 1-year & 2-year & 10-year & \\
\hline$\overline{\text { Full sa }}$ & ple & & & & & $\overline{\text { Full s }}$ & aple & & & \\
\hline Index & $0.699^{* * *}$ & 0.722 & $* * *$ & 0.778 " & *** & Index & $0.666^{* * *}$ & $0.770^{* * *}$ & 0.779 * & \\
\hline & $(0.133)$ & $(0.103)$ & & $(0.111)$ & & & $(0.196)$ & $(0.154)$ & $(0.133)$ & \\
\hline R-sq & 0.021 & 0.033 & & 0.024 & & R-sq & 0.009 & 0.016 & 0.015 & \\
\hline$\overline{Z I R P(}$ & $2 / 11 / 2008-1 / 2$ & 1/2015) & & & & $\overline{\text { QQE-2 }}$ & $\mathrm{RP}(4 / 4 / 201$ & $2 / 15 / 2016)$ & & \\
\hline Index & $0.301^{* *}$ & 0.350 & $* * *$ & $0.550 *$ & *** & Index & 0.086 & 0.183 & 0.118 & \\
\hline & $(0.133)$ & $(0.115)$ & & (0.199) & & & $(0.274)$ & $(0.249)$ & $(0.286)$ & \\
\hline R-sq & 0.009 & 0.015 & & 0.012 & & K-sq & 0.000 & 0.003 & 0.001 & \\
\hline NIRP & $/ 22 / 2015-1 / 3$ & (2018) & & & & $\mathrm{QQB}$ & IRP $(2 / 16 / 20$ & $-1 / 31 / 2018)$ & & \\
\hline Index & -0.015 & 0.008 & & 0.129 & & Index & $-1.036^{*}$ & -0.089 & -0.333 & \\
\hline & $(0.240)$ & $(0.232)$ & & $(0.271)$ & & & $(0.569)$ & $(0.358)$ & $(0.255)$ & \\
\hline R-sq & 0.000 & 0.000 & & 0.001 & & R-sq & 0.012 & 0.000 & 0.006 & \\
\hline
\end{tabular}

Notes:

i) Heteroscedasticity-corrected standard errors are reported in parenthesis.

ii) A constant is included in all estimations but associated coefficient estimates and standard errors are not reported for brevity.

iii) ${ }^{* * *}, *^{* *}$, and ${ }^{*}$ represent statistical significance at $1 \%, 5 \%$, and $10 \%$ levels, respectively. 
Table 4. Baseline results: Monthly frequency

a) Germany

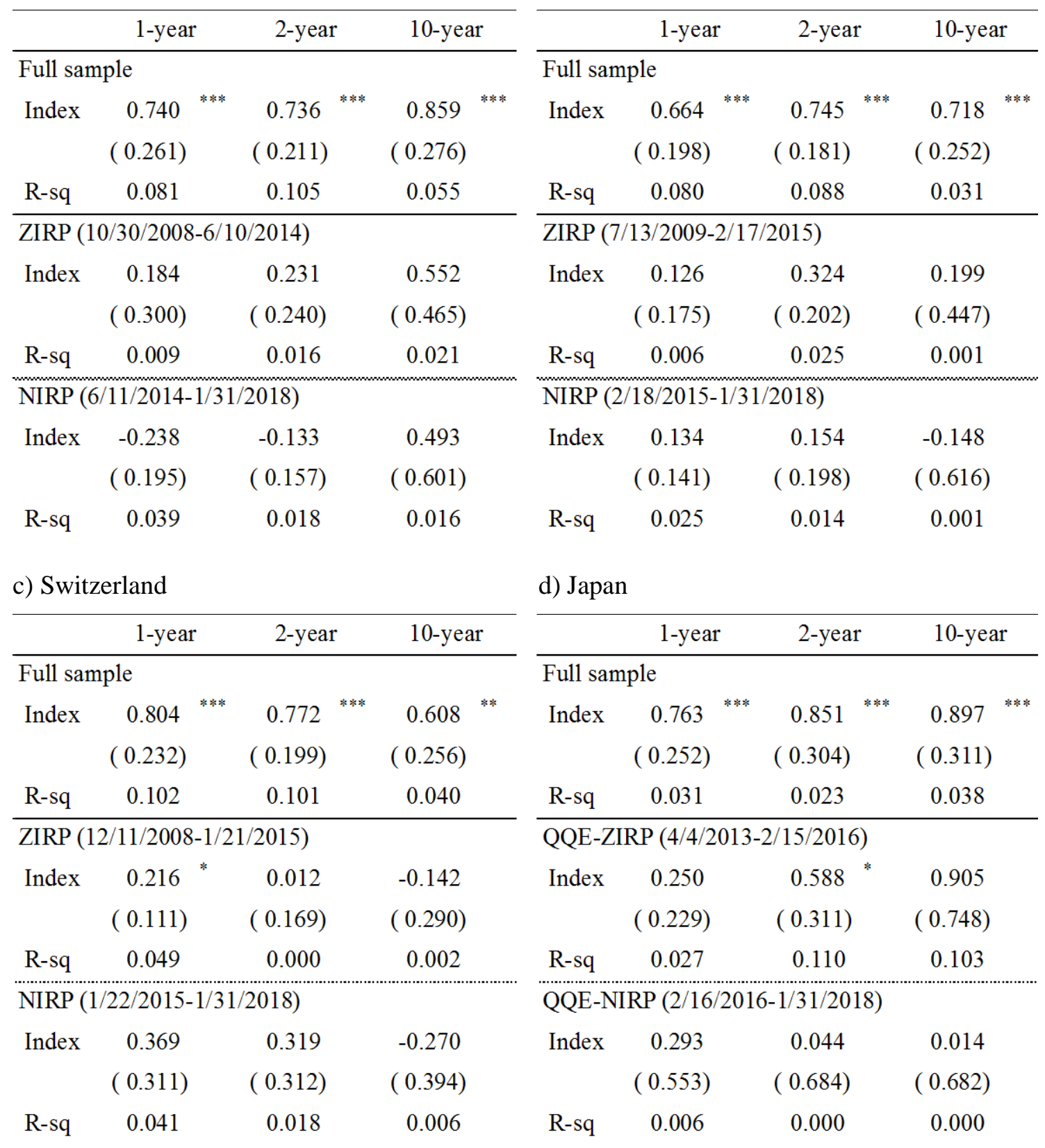

Notes: See notes to Table 3. 
Table 5. Regression results of principal components

a) Germany

\begin{tabular}{|c|c|c|c|c|c|c|c|c|c|}
\hline & 1st PC & 2nd PC & & 3rd PC & & $1 \mathrm{st} P C$ & 2nd PC & $3 \mathrm{rd} \mathrm{PC}$ & \\
\hline Full sar & ple & & & & Full sa & pple & & & \\
\hline Index & $0.770^{* * *}$ & 0.366 & $* * *$ & $0.567^{* * *}$ & Index & $0.936^{* * *}$ & 0.760 & 0.843 & $* * *$ \\
\hline & $(0.068)$ & $(0.141)$ & & $(0.186)$ & & $(0.081)$ & $(0.088)$ & $(0.178)$ & \\
\hline R-sq & 0.062 & 0.003 & & 0.005 & R-sq & 0.068 & 0.041 & 0.010 & \\
\hline ZIRP (1) & $0 / 30 / 2008-6 / 1$ & $0 / 2014)$ & & & $\mathrm{ZIRP}$ & $/ 13 / 2009-2 / 17$ & (2015) & & \\
\hline Index & $0.548^{* * *}$ & -0.685 & $* * *$ & -0.063 & Index & $0.945^{* * *}$ & 0.429 & 0.895 & \\
\hline & $(0.139)$ & $(0.200)$ & & $(0.210)$ & & $(0.183)$ & $(0.135)$ & $(0.376)$ & \\
\hline R-sq & 0.030 & 0.011 & & 0.000 & R-sq & 0.050 & 0.012 & 0.009 & \\
\hline NIRP & $/ 11 / 2014-1 / 31$ & (2018) & & & NIR & $/ / 18 / 2015-1 / 31$ & /2018) & & \\
\hline Index & 0.183 & -0.330 & & 0.034 & Index & $0.570^{* * *}$ & 0.329 & 0.164 & \\
\hline & $(0.113)$ & $(0.365)$ & & $(0.204)$ & & $(0.145)$ & $(0.185)$ & (0.299) & \\
\hline R-sq & 0.006 & 0.002 & & 0.000 & R-sq & 0.043 & 0.017 & 0.001 & \\
\hline
\end{tabular}

c) Switzerland

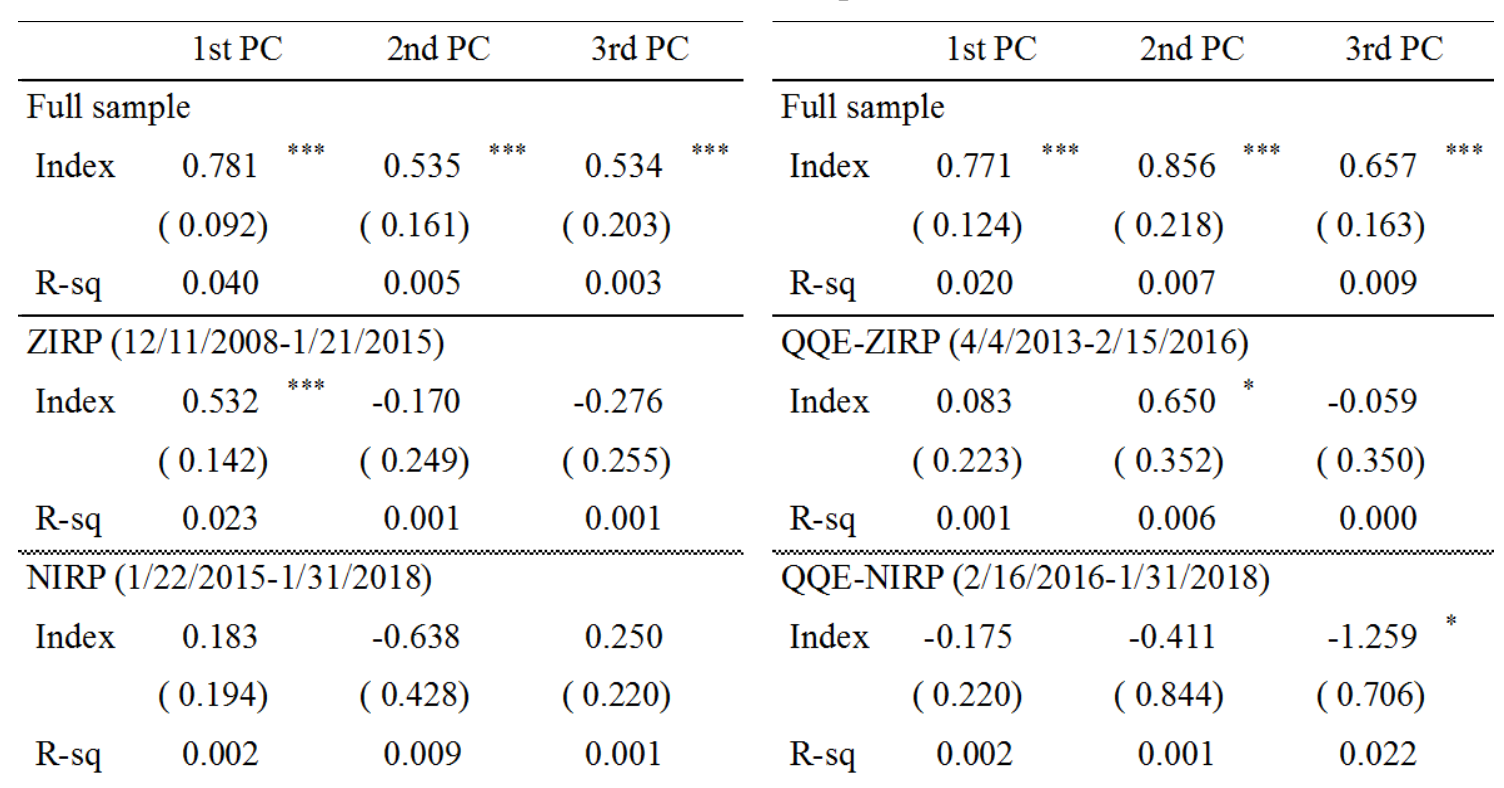

Notes: See notes to Table 3. b) Sweden

d) Japan 
Table 6. Baseline results for UK: Daily frequency

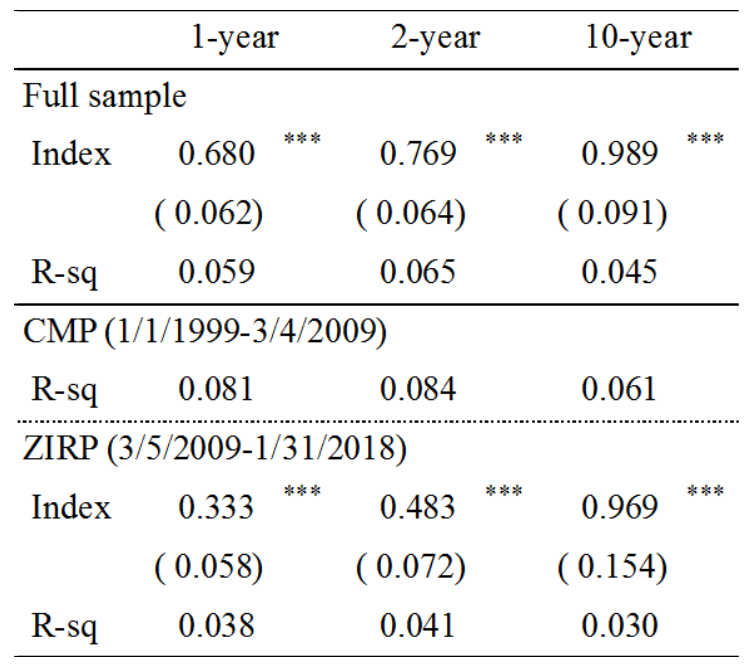

Notes: See notes to Table 3. 